\title{
Computational Analysis and Optimization of Spiral Plate Heat Exchanger
}

\author{
K. Pradeep Mohan Kumar ${ }^{1 \dagger}$, V. Vijayan², B. Suresh Kumar², C. M. Vivek ${ }^{3}$ and S. Dinesh² \\ ${ }^{1}$ SRM Institute of Science and Technology, Chennai, Tamil Nadu, India \\ ${ }^{2}$ K. Ramakrishnan College of Technology, Trichy, Tamil Nadu, India \\ ${ }^{3}$ Periyar Maniammai University, Thanjavur, Tamil Nadu, India \\ †Corresponding Author Email: pradeep_nv2004@yahoo.co.in
}

(Received May 15, 2018; accepted July 18, 2018)

\begin{abstract}
From the past few decade, many manufacturing industries are using heat exchangers for reducing the energy consumption and hence reducing the fuel costs. Most widely used types of heat exchangers in industries are Double Pipe Heat Exchangers and Shell \& Tube Heat Exchangers. It is recently that industry people and researchers are becoming more aware of the advantage of using Spiral Heat Exchangers for heat transfer between two different fluids.A Spiral Heat Exchanger is formedby a coiled sheet arrangement with two channels coiled one around the other. The distance between the sheets is kept constant to maintain the area of cross section through out the spiral path of the channels. In this work, flow pattern and heat transfer in a Spiral Heat Exchanger are analyzed using a couterflow model geometry. The results obtained for the fluid flow and heat transfer gives an idea about how we can optimize the flow rate of the fluids thus increasing the efficiency of the heat exchanger.
\end{abstract}

Keywords: Heat exchanger; Computational analysis; Geometric modelling; Flow analysis; Fluid structure interaction.

\section{INTRODUCTION}

In eighteenth century, it was imagined that a fluid flows from hot body to cold body, which they called it as 'caloric'. Later it was found that, it is the energy that is flowing from hotter bodies to colder bodies. There is always the flow of energy from hotter bodies to colder bodies. Heat transfer occurs in every medium. Overall energy of the universe always remains constant. And there will always be losses in the amount of heat transferred. It can be stated as heat flux is directly proportional to temperature gradient along the direction. Here proportionality constant ' $\mathrm{k}$ ' is called as thermal conductivity of the material. Thermal conductivity has the units $\mathrm{W} / \mathrm{m}$.K. The negative sign is because heat transfers from higher temperature value to a lower temperature value. Thermal conductivity is considered as thermal property of materials which is mostly obtained from experiments. Thermal conductivity value for a particular substance at particular temperature remains constant.

The temperature difference along $\mathrm{x}$-direction can be obtained by insulating all the four faces of the block and allowing th heat transfer only in the required direction. This is shown in following Figure 1where temperature $T_{1}$ on one surface is greater than the temperature $\mathrm{T}_{2}$ on the other side of the block. And heat transfer occurs from surface of temperature $T_{1}$ to the surface of temperature $\mathrm{T}_{2}$.

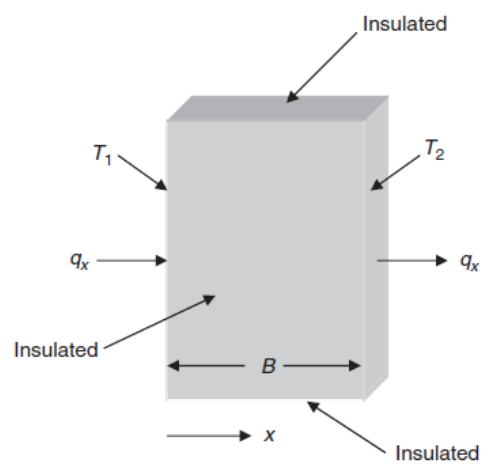

Fig. 1. One Dimensional Heat Transfer

Heat transfer may or may not lead to phase transformation. Phase transformation is most common where heat transfer is involved. Different types of phase transformations that occur during heat transfer are: condesation, sublimation, 
vaporization, deposition, freezing and melting. Spiral Plate type Heat Exchangers (SPHE) shortly referred to as Spiral heat Exchangers contains two flow channels binded spirally to produce first and second flow channels for respective first (hot/cold) and second (hot/cold) fluids used for heat exchanging. Fluid channels are separated by single metal sheet in between them. And the temperature difference can be seen in both sides of the fluid channel, till the periphery of the body. The metallic sheets used to form the spiral are spaced at equal distances using spacer studs/spacing pins welded on both sides to the sheets to form a uniform cross sectional area for the fluid flow channels. These spacer studs enable us to provide required thickness for the fluid channels. Commonly used materials for fabrication of spiral plate type heat exchanger are nickel, stainless steel, carbon steel, nickel, titanium, nickel-alloys, copper-alloys, etc. Similar model was also designed by Nuntaphan (2005). They performed experimental work on Crimped Spiral fins as shown in Figure 2. Observations were recorded for several runs at different fin heights, fin spacing's and for different tube diameters. This type of heat exchanger can be used for air cooled type of heat exchangers. Larger the tube diameter, lesser is the heat transfer coefficient and more is the pressure drop across the flow by Lakshmanaprabu (2017). This experimentation also gave a perspective on optimization of diameter range for helical type heat exchangers. They concluded that air side heat transfer coefficient was impacted a lot by tube diameters. This type of work on fins gives idea on how to modify the flow in spiral plate type heat exchangers. This design itself can be used for helical flow heat exchanger model, with the periphery of the Spiral Plate Type Heat Exchangers:

Chowdhury (1984) performed analytical studies on distribution of temperature in spiral plate type heat exchangers. They developed formulae for Logarithmic Mean Temperature Difference and efficiency for Design calculations of the spiral plate type heat exchanger. Calculations were made for Logarithmic Mean Temperature Difference correction factors. These were plotted against an expression formed using the number of transfer units and number of turns for the spiral heat exchanger, used for the numerical calculations. From these calculations LMTD correction factor was modelled to estimate the efficiency of the heat exchanger. Bes \& Roetzel (1993) also worked on similar type of problem by considering analytical calculations on counter flow spiral plate type heat exchanger. They proposed a dimensionless criterion number for use in calculation of Correction factor for logarithmic mean temperature difference. This theory's accuracy was considered to be increasing with increase in the number of turns for the fluid channels. Both of these analytical calculations helped in analysing the spiral plate type heat exchangers with more accuracy when compared to experimental values. Present work can be developed to use these correction factors and perform a better analysis. Koot (1991) patented a type of spiral plate type heat exchanger design. In the patent he described the design of spiral plate type heat exchanger to contain an additional third channel of flow along with the two regular flow channels. In this type of heat exchanger, one can have the third fluid flowing axially while other two fluids flow in spiral pattern. This type of heat exchanger mainly helps in industries where preheating of the compounds or chemicals is required. Picón-Núñez, (2007) found a shortcut approach for design of spiral plate type heat exchanger. The idea behind their study is to give fewer inputs like external spiral diameter and plate thickness as initial values and to find out the number of turns based on the required pressure drop for the fluid flow channel. Following figure 2.5 shows the dimensions for a spiral plate type heat exchanger. Number of turns or the inner diameter was changed accordingly to get the design parameters. This process takes the approach of iterative procedure to converge at the required solution to match the heat duty and pressure drop across the spiral heat exchanger.

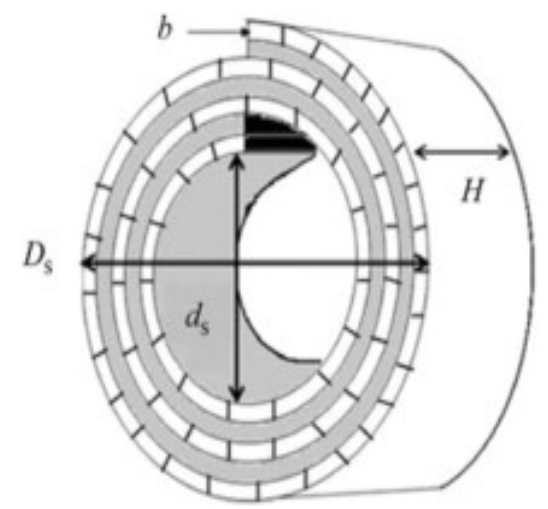

Fig. 2. Spiral Plate Type Heat Exchanger with Dimensions

(Picón-Núñez et al., 2007)

Spiral plate type heat exchanger can be analysed using Computational Fluid Dynamics, by simulating both conduction and convection in the domain. Conduction occurs through the solid continuum while the convection part is in fluid continua. Conduction and convection involved systems can be considered as Conjugate Heat Transfer systems. Following are the previous works done by using Conjugate Heat Transfer in CFD.

Niggemann, (1991) patented a technology in spiral plate type heat exchanger where he used the concept of concentric centre for both the fluid flow channels in spiral plate type heat exchanger. Laminated concentric fluid channels were wound in spiral pattern to produce the final spiral plate type heat exchanger. Heat transfer occurs the same way in between the hot fluid zone and cold fluid zone. This pattern creates heat transfer efficiency more or less close to the general design. It has an advantage of easy fabrication compared to classic types of spiral heat exchanger designs. Dongwu (2003) worked on project that deals with spiral plate type heat exchangers. His work is related to the calculations of geometry for semi-spirals in spiral heat exchangers. He divided the spiral path 
into two semi-circles by partitioning the spiral. Following figure 2.8 shows the way of partitioning the heat exchanger. He related number of turns for spiral heat exchanger with the dimensions mentioned in the figure. Devois (1995) are among the few members who worked on numerical analysis of spiral plate type heat exchanger. Their work is based on computational simulation of spiral plate type heat exchanger. They analysed the system by using a two dimensional model for flow simulation and calculations. Both Steady state and transient state analysis was made and the flow was analysed successfully. Following figure 2.9 shows the model considered for the simulation analysis. Nunez (2007) worked on a different approach for design of spiral plate type heat exchanger. This work is applicable to counter-current flow of single phase flow systems. Pressure of flowing fluid is related to the coefficient of heat transfer through the heat exchanger geometrical measurements. This helps in calculation of smallest dimensions possible for design of the spiral plate type heat exchanger. The channel thickness for both fluid streams is allowed to be modified in order to optimize the pressure drop of the fluid. The results are compared with the experimental values available for such design, and it is concluded that the design approach is in agreement with the values and can be used reliably. Yapıcı \& Albayrak (2004) analysed the conjugate heat transfer in a circular pipe heat externally. This has several important applications in engineering field. Such heating is used in direct fire heating systems that are widely applicable in petroleum industries. In this study they analysed axial and radial conduction of heat. They also estimated thermal stress in the pipe with inputs as non-uniform or uniform heat fluxes in fully developed flows. This type of heat transfer is considered as forced convection process as the fluid in the pipe is being pumped by an external force. They performed two dimensional analysis along laminar boundary layer using steady-state heat conduction through the solid material. The fluid under consideration is water. They simulated the flow using FLUENT 4.5 and HEATING7 codes for numerical analysis. The temperature distribution curves inside the pipe wall were calculated and analysed. The temperature distribution for fluid zone was also analysed using the results obtained. The following figure 2.14 shows the temperature variation along axial direction and are found to be reasonably correct for different velocities. Kanaris (2005)attempted to study the flow and heat transfer variations in compact heat exchangers. In an attempt to understand about such a situation, they used a straight channel through which the fluid is flowing. The surface of the plate considered is corrugated, which is common in many compact plate type heat exchangers. They did the numerical simulations using CFX for their study. The model used for simulation is two equation SST model for turbulence. First they analysed the isothermal flow of fluid and then they incorporated the heat parameters for heat transfer analysis. The system considered for heat transfer is, water entering at $60^{\circ} \mathrm{C}$ at inlet and wall temperature at $20^{\circ} \mathrm{C}$. The results obtained for heat transfer coefficients were compared with the previous experimental values. And they are in good agreement with the simulated values. They also estimated the mean heat transfer coefficients and found them to be reasonable for such type of flow situations. This helps in understanding the flow patterns and temperature variations in heat exchangers like plate type heat exchangers. The geometry considered for the flow and heat transfer analysis is shown in the figure 2.15. Huang (2003) conducted a study of conjugate heat transfer and turbulent flow in concentric annuli with inner rod moving. The analysis was made using numerical simulation of the flow and heat transfer. Modified k-epsilon two equation turbulent model was used to perform the numerical calculations. The temperature distribution is in agreement with the variation of speed of the central rod movement. As the speed is reduced the temperature profile transferring is reduced. Below is the figure 2.16 showing the system of analysis. Radius of rod is R1 and the annulus thickness is R2-R1. Jahangeer (2007)they studied heat dissipation in a system consisting of nuclear reactor. The surface of nuclear reactor dissipating heat is considered to be rectangular in shape. Study is performed on a two dimensional flow condition with a rectangular surface at the centre emitting heat into the fluid. The equations at the boundary layer are discretized using finite differences fully implicit scheme. And second order central differencing scheme is performed for discretization of energy equation in solid medium. The calculated heat transfer parameters are compared with the experimental values. And they found that the values agree with the realistic observations. Figure 2.17 shows the flow pattern over the hot nuclear reactor surface that is considered for analysis. Tsai (1999) are prominent among researchers who worked on heat transfer simulations in twentieth century. They worked on the numerical modelling and application of conjugate heat transfer i.e. heat transfer involving conduction and convection. The surface of fins considered, itself is a nonplain and shrinked surface. These wavy areas over the surface increase the heat transfer area and thus increasing heat transfer efficiency.

\section{MODELLING OF SPIRAL PLATE TYPE HEAT EXCHANGER}

Spiral plate type heat exchanger design process involves determining several flow variables and heat transfer variables like pressure drops, equivalent diameters of both flow channels and Reynolds number of the two fluids flowing in the heat exchanger. CFD simulation of spiral plate type heat exchanger is done in three different steps. Work Process covers all the three main stages of CFD analysis: Pre-processing, Solution and Post-Processing. These steps are 
individually described as follows:

\subsection{Geometry Modelling by JAFM}

Spiral plate type heat exchanger is modelled using Catia v5. Geometry creation in this type of simulations plays an important role. Small change in the geometry may impact a lot on expected results. Geometry for present work is created using non-standard values of dimensions. Future work on this involves comparison of these results with CFD analysis on a SPHE created using standard dimensions. Following steps describe how the complex spiral heat exchanger geometry is created using Catia v5 as shown in Figure 3.

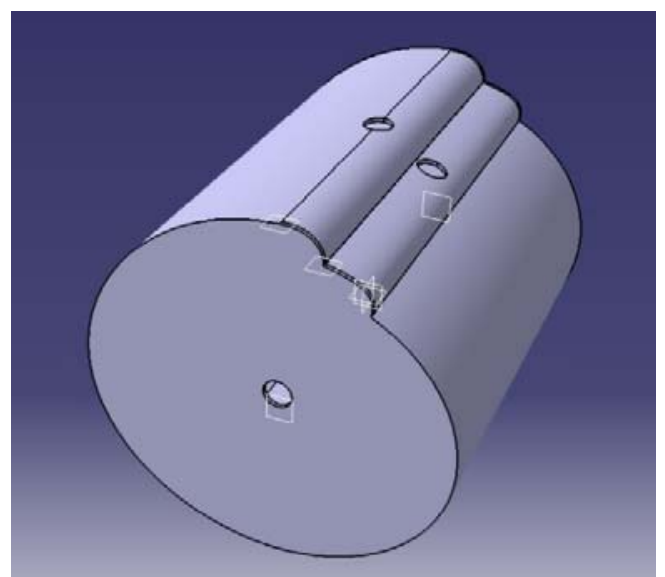

Fig. 3. Final Geometry after Modelling

Table 1 Continuum Types for SPHE Zones

\begin{tabular}{|c|c|}
\hline Volume & Continuum Type \\
\hline $\begin{array}{c}\text { Flow channel for hot fluid } \\
\text { (inner) }\end{array}$ & Fluid \\
\hline $\begin{array}{c}\text { Flow channel for cold } \\
\text { fluid (outer) }\end{array}$ & Fluid \\
\hline Solid volume & Solid \\
\hline
\end{tabular}

\subsection{Meshing}

Geometry created is imported into Star-CCM+ using 3D CAD Model import. The Continuum zones are then renamed as hot, cold and solid zones. The inlets and outlets of heat exchanger should be separated and renamed as hot inlet, hot outlet, cold inlet and cold outlet respectively so that they do not combine with walls. The reference value for Base Size is set to $0.02 \mathrm{~m}$, and Per-region meshing is chosen to create separate mesh zones for each continuum. Prism layers are created with Stretching ratio 1.2 and maximum number of layers as 5 .

Table 2 Number of Cells in SPHE Mesh Created

\begin{tabular}{|c|c|}
\hline Zone & Number of grid cells \\
\hline Cold Fluid Channel & 186240 \\
\hline Hot Fluid Channel & 152603 \\
\hline Solid Zone & 733290 \\
\hline
\end{tabular}

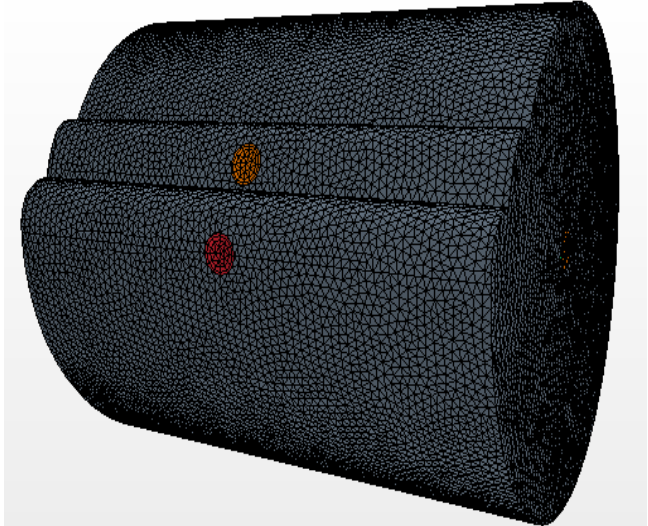

Fig. 4. Mesh Scene for Complete Body

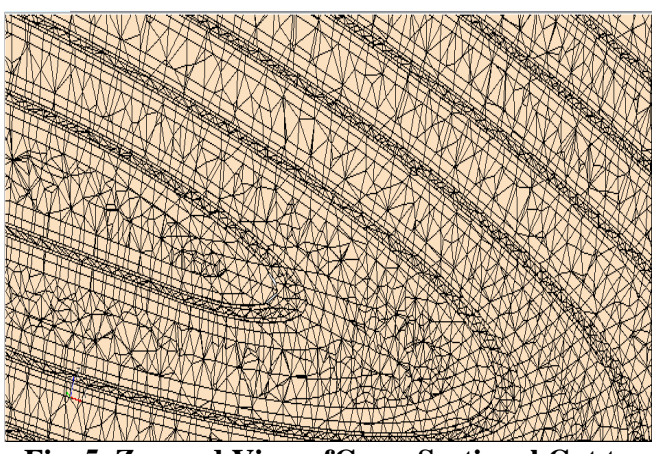

Fig. 5. Zoomed View ofCross Sectional Cut to Show Individual Mesh Regions of SPHE

\section{RESULTS AND DISCUSSIONS}

Simulation of spiral plate type heat exchanger considered is done using CFD software Star$\mathrm{CCM}+$.Solution of this conjugate heat transfer problem is considered as converged when the residual plot remains parallel to the $\mathrm{X}$-axis.Results of the simulation are plotted using vector scenes and scalar scenes created using Star-CCM+.Three flow cases are considered for the study.

\subsection{Case 1: Hot Fluid Velocity $=1.5 \mathrm{~m} / \mathrm{s}$; Cold Fluid Velocity $=3 \mathrm{~m} / \mathrm{s}$}

Inlet velocity of hot fluid given is $1.5 \mathrm{~m} / \mathrm{s}$. The velocity changes across the spiral channel can be seen in the following contour plots. Velocity vectors at the inlet of the hot fluid should be perpendicular to the spiral flow. These velocity vectors of the hot fluid at inlet are shown in the following Figure 6.The plane in which vectors are plotted are $10 \mathrm{~mm}$ away from the ending of the heat exchanger. The vectors shown in the above Figure are in agreement with the realistic situation as the hot fluid enters in the direction of the width of the spiral plate type heat exchanger. The velocity of the fluid particles at the center of the inlet vectors shown are at high velocity. While the vectors far from the center of those fluid vectors at inlet are comparatively less. This is because of the viscous forces exerted by the circular wall at inlet. 


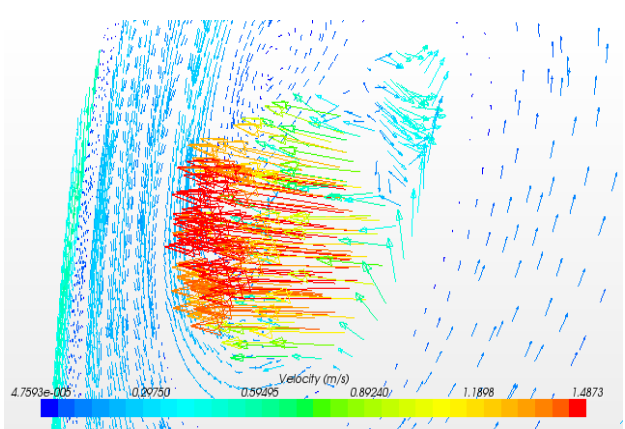

Fig. 6. Velocity Vectors at the Inlet of Hot Fluid at $\mathrm{X}=-\mathbf{0 . 1 4}$

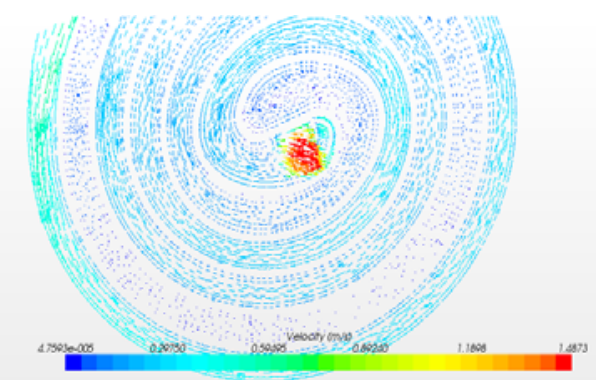

Fig. 7. Full View of the Plane at $X=-0.14 m$

Decrease in temperature of hot fluid as we move from inlet of hot fluid to the periphery of the spiral heat exchanger is shown in the following Figure 8.Graph shows a close to linear variation of temperature in the hot fluid side of heat exchanger. Temperature of hot fluid is varying from $350 \mathrm{~K}$ at the inlet to $329 \mathrm{~K}$ near the outlet of the fluid. The temperature data for this graph is collected at seven different points along the length of the spiral flow channel.

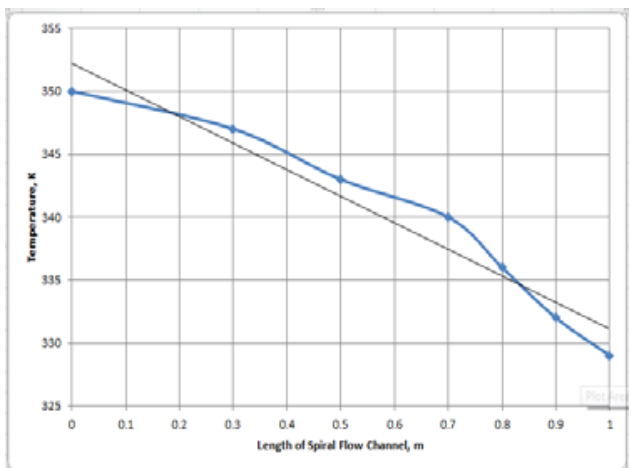

Fig. 8. Hot Fluid Temperature Variation Along the Length

Increase in temperature of cold fluid as we move from periphery of the spiral heat exchanger to the inlet of hot fluid is shown in the following Figure 9.Graph shows a close to linear variation of temperature in the hot fluid side of heat exchanger. Temperature of cold fluid is varying from $293 \mathrm{~K}$ at the inlet to $296.2 \mathrm{~K}$ near the outlet of the fluid. The temperature data for this graph is collected at seven different points along the length of the spiral flow channel. Figure 9 shows the variation in temperature values for all regions at $\mathrm{YZ}$ plane .i.e. at the center of the width of heat exchanger.

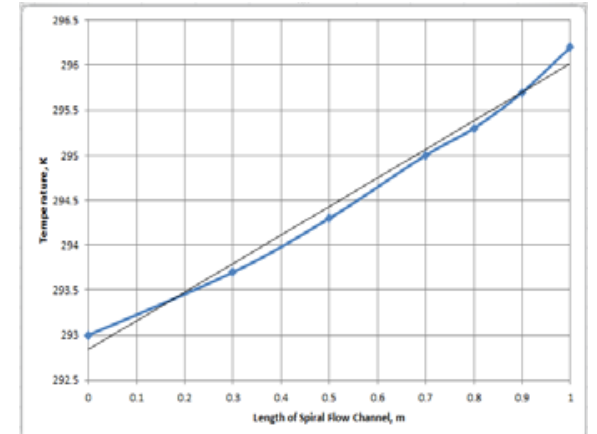

Fig. 9. Cold Fluid Temperature Variation along the Length

\subsection{Case 2: Hot Fluid Velocity $=3 \mathrm{~m} / \mathrm{s}$; Cold Fluid Velocity $=3 \mathrm{~m} / \mathrm{s}$}

Inlet velocity for both fluid inlets is provided as 3 $\mathrm{m} / \mathrm{s}$. The velocity changes across the spiral channel can be seen in the following contour plots. The velocity vectors of the hot fluid at inlet are shown in the following Figure 10.

The vectors shown in the above figure are in agreement with the realistic situation as the hot fluid enters in the direction of the width of the spiral plate type heat exchanger. Following Figure 11 shows velocity vectors of hot fluid in a plane cut to show the width of the spiral plate type heat exchanger. The velocity vectors show that the hot fluid is trying to maintain its direction almost till the end of the spiral plate type heat exchanger width. The velocity of the hot fluid decreased in the outer cuts of the hot fluid channel. This is due to the pressure drop occurring due to the flow of the fluid. Also there is formation of stagnant region or recirculation region at the end of the width along the axis of hot fluid inlet.

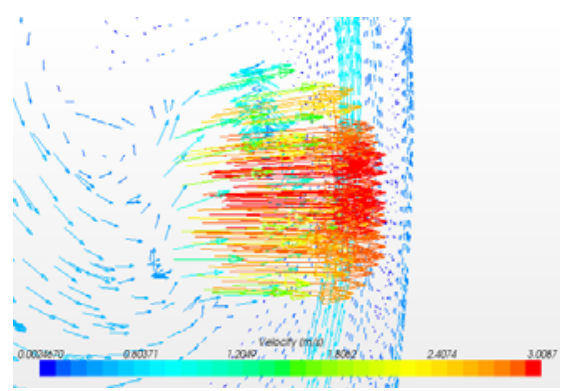

Fig. 10. Velocity Vectors at the Inlet of Hot Fluid at $\mathrm{X}=-\mathbf{0 . 1 4}$

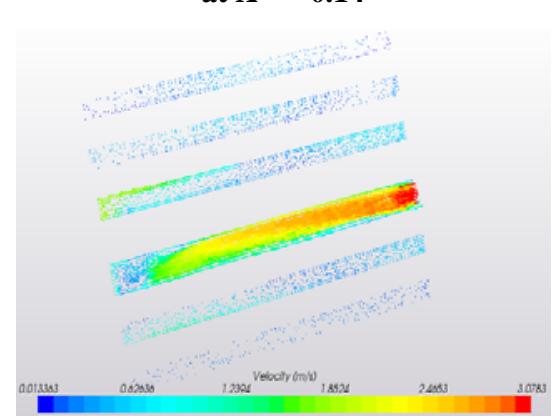

Fig. 11. Velocity Vectors Along Axial Direction for Hot Fluid Channel 


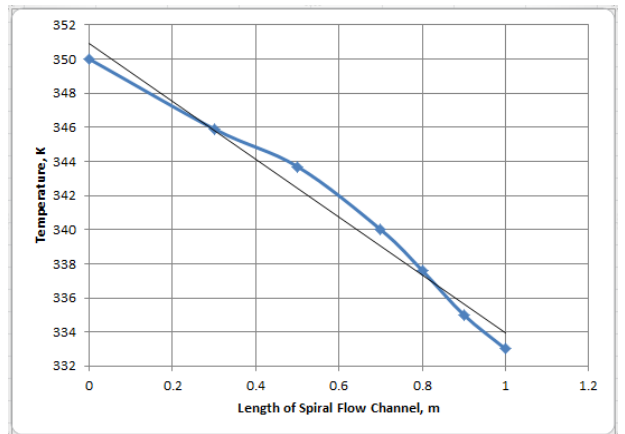

Fig. 12. Hot Fluid Temperature Variation Along the Length

Increase in temperature of cold fluid as we move from periphery of the spiral heat exchanger to the inlet of hot fluid is shown in the following Figure 13.Graph shows a close to linear variation of temperature in the hot fluid side of heat exchanger. Temperature of cold fluid is varying from $293 \mathrm{~K}$ at the inlet to $297 \mathrm{~K}$ near the outlet of the fluid. The temperature data for this graph is collected at seven different points along the length of the spiral flow channel.

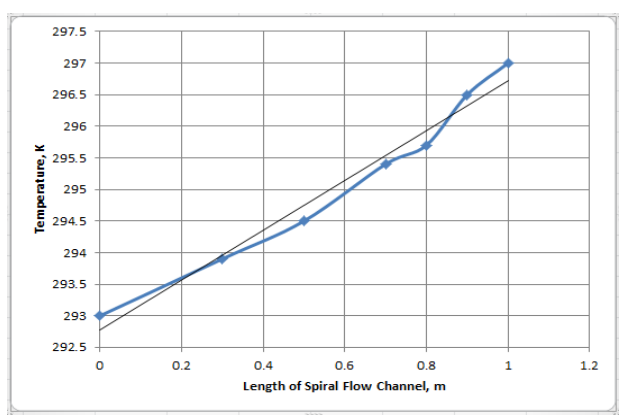

Fig. 13. Cold Fluid Temperature Variation along the Length

\subsection{Case 3: Hot Inlet Velocity $=1.5 \mathrm{~m} / \mathrm{s}$; Cold Inlet Velocity $=1.5 \mathrm{~m} / \mathrm{s}$}

Inlet velocity for both fluid inlets is provided as 1.5 $\mathrm{m} / \mathrm{s}$. The velocity changes across the spiral channel can be seen in the following contour plots.The velocity vectors of the hot fluid at inlet are shown in the following Figure 14.

The vectors shown in the above figure are in agreement with the realistic situation as the hot fluid enters in the direction of the width of the spiral plate type heat exchanger. Following Figure 15 shows velocity vectors of hot fluid in a plane cut to show the width of the spiral plate type heat exchanger. The velocity vectors show that the hot fluid is trying to maintain its direction almost till the end of the spiral plate type heat exchanger width. The velocity of the hot fluid decreased in the outer cuts of the hot fluid channel. This is due to the pressure drop occurring due to the flow of the fluid. Also there is formation of stagnant region or recirculation region at the end of the width along the axis of hot fluid inlet. This flow has occurred in all three cases of velocity variations.

The distance travelled by the hot fluid in the axial direction is greater in this case compared to the distance travelled by hot fluid in case 1 and case 2.The velocity vectors show that the hot fluid is trying to maintain its direction almost till the end of the spiral plate type heat exchanger width. The velocity of the hot fluid decreased in the outer cut sections of the hot fluid channel. This is due to the pressure drop occurring due to the flow of the fluid. The maximum velocity shown in the vectors is more than the velocity given for the cold fluid. This is because of the pressure gradients at the region. Figure 16 shows velocity vectors of cold fluid in a plane cut to show the width of the spiral plate type heat exchanger. The flow pattern is almost the same for this case when compared to the flow pattern of fluids in case 1 and case 2 .

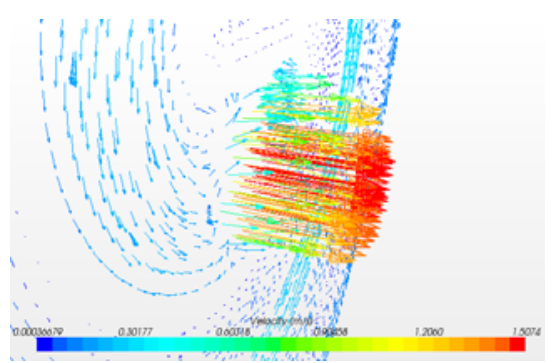

Fig. 14.Velocity Vectors at the Inlet of Hot Fluid at $\mathrm{X}=-\mathbf{0 . 1 4}$

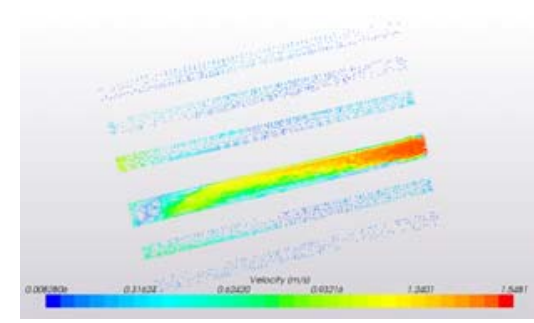

Fig. 15. Velocity Vectors along Axial Direction for Hot Fluid Channel

Increase in temperature of cold fluid as we move from periphery of the spiral heat exchanger to the inlet of hot fluid is shown in the following Figure 17.Graph shows a close to linear variation of temperature in the hot fluid side of heat exchanger. Temperature of cold fluid is varying from $293 \mathrm{~K}$ at the inlet to $298 \mathrm{~K}$ near the outlet of the fluid. The temperature data for this graph is collected at seven different points along the length of the spiral flow channel.

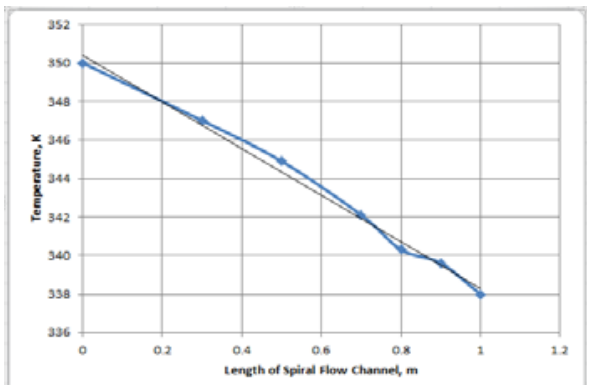

Fig. 16. Hot Fluid Temperature Variation along the Length

Increase in temperature of cold fluid as we move from periphery of the spiral heat exchanger to the inlet of hot fluid is shown in the following Figure 17.Graph shows a close to linear variation of temperature in the hot fluid side of heat exchanger. Temperature of cold fluid is varying from $293 \mathrm{~K}$ at the inlet to $298 \mathrm{~K}$ near the outlet of the fluid. The temperature data for this graph is collected at seven different points along the length of the spiral flow channel. 


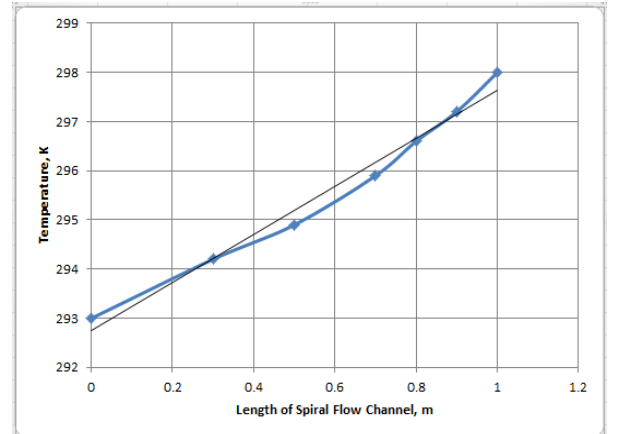

Fig. 17. Cold Fluid Temperature Variation along the Length

\subsection{Results from FORTRAN Code for Spiral Plate type Heat Exchanger:}

Table 3 Heat Transfer Parameters for Case-1

(For Case 1: Hot Fluid Velocity $=1.5 \mathrm{~m} / \mathrm{s}$; Cold Fluid Velocity $=3 \mathrm{~m} / \mathrm{s}$ )

\begin{tabular}{|c|c|c|}
\hline Variable & Value & Units \\
\hline LMTD & 44.306 & $\mathrm{~K}$ \\
\hline Outside Spiral Diameter & 0.22185 & $\mathrm{~m}$ \\
\hline $\begin{array}{c}\text { Equivalent Diameter of } \\
\text { Hot Fluid }\end{array}$ & 0.02857 & $\mathrm{~m}$ \\
\hline $\begin{array}{c}\text { Equivalent Diameter of } \\
\text { Cold Fluid }\end{array}$ & 0.02857 & $\mathrm{~m}$ \\
\hline $\begin{array}{c}\text { Reynolds Number for } \\
\text { Cold Fluid }\end{array}$ & 25037.7 & -- \\
\hline $\begin{array}{c}\text { Reynolds Number for } \\
\text { Hot Fluid }\end{array}$ & 31211.73 & -- \\
\hline $\begin{array}{c}\text { Critical Reynolds } \\
\text { Number for Cold Fluid }\end{array}$ & 10379.85 & -- \\
\hline $\begin{array}{c}\text { Critical Reynolds } \\
\text { Number for Hot Fluid }\end{array}$ & 10379.85 & -- \\
\hline $\begin{array}{c}\text { Overall Heat Transfer } \\
\text { Coefficient }\end{array}$ & 7.056 & $\mathrm{~W} / \mathrm{m} 2 . \mathrm{K}$ \\
\hline $\begin{array}{c}\text { Pressure Drop Across } \\
\text { Cold Fluid }\end{array}$ & 4915.6 & $\mathrm{~Pa}$ \\
\hline $\begin{array}{c}\text { Pressure Drop Across } \\
\text { Hot Fluid }\end{array}$ & 1082.14 & $\mathrm{~Pa}$ \\
\hline
\end{tabular}

Table 4 Heat Transfer Parameters for Case-2

(For Case 2: Hot Fluid Velocity $=3 \mathrm{~m} / \mathrm{s}$; Cold Fluid Velocity $=3 \mathrm{~m} / \mathrm{s}$ )

\begin{tabular}{|c|c|c|}
\hline Variable & Value & Units \\
\hline LMTD & 46.196 & $\mathrm{~K}$ \\
\hline $\begin{array}{c}\text { Outside Spiral } \\
\text { Diameter }\end{array}$ & 0.22185 & $\mathrm{~m}$ \\
\hline $\begin{array}{c}\text { Equivalent Diameter of } \\
\text { Hot Fluid }\end{array}$ & 0.02857 & $\mathrm{~m}$ \\
\hline $\begin{array}{c}\text { Equivalent Diameter of } \\
\text { Cold Fluid }\end{array}$ & 0.02857 & $\mathrm{~m}$ \\
\hline $\begin{array}{c}\text { Reynolds Number for } \\
\text { Cold Fluid }\end{array}$ & 25037.7 & -- \\
\hline $\begin{array}{c}\text { Critical Fluid Reynolds } \\
\text { Number for Cold Fluid }\end{array}$ & 10379.85 & -- \\
\hline $\begin{array}{c}\text { Critical Reynolds } \\
\text { Number for Hot Fluid }\end{array}$ & 10379.85 & -- \\
\hline $\begin{array}{c}\text { Overall Heat Transfer } \\
\text { Coefficient }\end{array}$ & 7.2643 & $\mathrm{~W} / \mathrm{m} 2 . \mathrm{K}$ \\
\hline $\begin{array}{c}\text { Pressure Drop Across } \\
\text { Cold Fluid }\end{array}$ & 4915.6 & $\mathrm{~Pa}$ \\
\hline $\begin{array}{c}\text { Pressure Drop Across } \\
\text { Hot Fluid }\end{array}$ & 4328.56 & $\mathrm{~Pa}$ \\
\hline
\end{tabular}

Table 5 Heat Transfer Parameters for Case-3

(For Case 3: Hot Fluid Velocity $=1.5 \mathrm{~m} / \mathrm{s}$; Cold Fluid Velocity $=1.5 \mathrm{~m} / \mathrm{s}$ )

\begin{tabular}{|c|c|c|}
\hline Variable & Value & Units \\
\hline LMTD & 48.416 & $\mathrm{~K}$ \\
\hline $\begin{array}{c}\text { Outside Spiral } \\
\text { Diameter }\end{array}$ & 0.22185 & $\mathrm{~m}$ \\
\hline $\begin{array}{c}\text { Equivalent Diameter } \\
\text { of Hot Fluid }\end{array}$ & 0.02857 & $\mathrm{~m}$ \\
\hline $\begin{array}{c}\text { Equivalent Diameter } \\
\text { of Cold Fluid }\end{array}$ & 0.02857 & $\mathrm{~m}$ \\
\hline $\begin{array}{c}\text { Reynolds Number for } \\
\text { Cold Fluid }\end{array}$ & 12518.83 & -- \\
\hline $\begin{array}{c}\text { Reynolds Number for } \\
\text { Hot Fluid }\end{array}$ & 31211.73 & -- \\
\hline $\begin{array}{c}\text { Critical Reynolds } \\
\text { Number for Cold } \\
\text { Fluid }\end{array}$ & 10379.85 & -- \\
\hline $\begin{array}{c}\text { Critical Reynolds } \\
\text { Number for Hot } \\
\text { Fluid }\end{array}$ & 10379.85 & -- \\
\hline $\begin{array}{c}\text { Overall Heat } \\
\text { Transfer Coefficient }\end{array}$ & 4.201291 & $\mathrm{~W} / \mathrm{m} 2 . \mathrm{K}$ \\
\hline $\begin{array}{c}\text { Pressure Drop Across } \\
\text { Cold Fluid }\end{array}$ & 1228.9 & $\mathrm{~Pa}$ \\
\hline $\begin{array}{c}\text { Pressure Drop Across } \\
\text { Hot Fluid }\end{array}$ & 1082.14 & $\mathrm{~Pa}$ \\
\hline
\end{tabular}

\section{CONCLUSIONS RECOMMENDATIONS}

AND

In this work, spiral plate type heat exchanger is analysed successfully by simulating the heat transfer simultaneously with two fluids flowing in separate channels separated by a metallic sheet. Initially, the work provides an idea on how to model the spiral plate type heat exchanger for Computational Fluid Dynamic analysis. This helps in understanding the modelling part and to improve the design for future advancements. The analysis can further be carried out for multi-phase systems .i.e. for fluids with dispersed solids and analyse how the spiral plate type heat exchanger has an advantage over other conventional heat Exchangers. Future work can also be done on the positioning of inlets and outlets for hot and cold fluids. From the present work, it is found that case 2 gave higher heat transfer coefficient compared to other two flow cases. Thus, it is recommended to analyse the system and then use the optimum conditions for heat transfer required. From 1930's spiral plate type heat exchangers have not changed much. Work can be carried out analysing different flow conditions and SPHE design can be optimized to increase the limits of operable pressures and temperatures. Work can also be done on positioning of joining pins to reduce the disturbance in flow caused by those pins. This opens a wide variety of analysing areas in the field of spiral plate type heat exchangers. Computational Fluid Dynamics simulation can also be done using Fluid Structure Interaction and analyse the life cycle of the spiral plate type heat exchangers. This provides industries with the time periods for maintenance and thus have optimum maintenance schedules to increase the productive period of the Spiral heat Exchanger. 


\section{REFERENCES}

Nuntaphan, A., T. Kiatsiriroat, C. C. and Wang (2005). Heat transfer and friction characteristics of crimped spiral finned heat exchangers with dehumidification. Applied Thermal Engineering 25(2-3), 327-340.

Lakshmanaprabu, S. K., A. W. Nasir and U. S. Banu (2017). Design of Centralized Fractional order PI Controller for Two Interacting Conical Frustum Tank Level Process. Journal of Applied Fluid Mechanics 10, 23-32.

Chowdhury, K., H. Linkmeyer, M. K. Bassiouny and H. Martin (1984). Analytical studies on the temperature distribution in spiral plate heat exchangers: Straightforward design formulae for efficiency and mean temperature difference. Chemical Engineering and Processing: Process Intensification 19(4), 183-190.

Bes, T. and W. Roetzel (1993). Thermal theory of the spiral heat exchanger. International Journal of Heat and Mass Transfer 36(3), 765-773.

Koot, L. W. (1991). SPIRAL HEAT EXCHANGER. Retrieved from http://www.freepatentsonline.com/EP0553238. html

Picón-Núñez， M. L. Canizalez-Dávalos, G. Martínez-Rodríguez and G. T. Polley (2007). Shortcut Design Approach for Spiral Heat Exchangers. Food and Bioproducts Processing 85(4), 322-327.

Niggemann, R. E. (1991). Patent US4993487 Spiral heat exchanger. Retrieved March 05, 2013,http://www.google.co.in/patents?hl=en\&l $r=\& v i d=$ USPAT4993487 \&id $=$

EnAAAAEBAJ\&oi $=$ fnd $\& d q=$ Spiral + Heat $+E x$ changer \&printsec $=$ abstract $\# v=$ onepage $\& q=S$ piral Heat Exchanger $\& f=$ false

Dongwu, W. (2003). Geometric calculations for the spiral heat exchanger. Chemical engineering \& technology, 26, 592-598.

Devois, J., J. Durastanti and B. Martin (1995). Numerical modelling of the spiral plate heat exchanger. Journal of Thermal Analysis 44, 305-312.

Nunez, M., L. Davalos and A. Fuentes (2007). Alternative design approach for spiral plate heat exchangers. Chemical Engineering, 183188.

Yapıcı, H., and B. Albayrak (2004). Numerical solutions of conjugate heat transfer and thermal stresses in a circular pipe externally heated with non-uniform heat flux. Energy Conversion and Management, 45(6), 927-937.

Kanaris, A. G., Mouza, A. A., S. V. Paras (2005). Flow and Heat Transfer in Narrow Channels with Corrugated Walls. Chemical Engineering Research and Design, 83(5), 460-468.

Huang, S., C. H. Chun (2003). A numerical study of turbulent flow and conjugate heat transfer in concentric annuli with moving inner rod. International Journal of Heat and Mass Transfer, 46(19), 3707-3716.

Jahangeer, S., M. K. Ramis and G. Jilani (2007). Conjugate heat transfer analysis of a heat generating vertical plate. International Journal of Heat and Mass Transfer, 50(1-2), 85-93.

Tsai, S. F., T. W. H. Sheu and S. M. Lee (1999). Heat transfer in a conjugate heat exchanger with a wavy fin surface. International Journal of Heat and Mass Transfer, 42(10), 17351745. 